\title{
Evaluación de Tres Métodos para Uso de Albúmina Sérica Bovina en el Sexado de Espermatozoides de Toros
}

\author{
Evaluation of Three Methods for Use of Bovine Serum Albumin in Bull \\ SPERMATOZOA SeXING
}

\author{
Gonzalo W. Gonzales Aparicio ${ }^{1,3}$, Próspero C. Cabrera Villanueva ${ }^{2}$
}

\section{Resumen}

\begin{abstract}
La investigación se hizo para determinar la posibilidad de variar la proporción de espermatozoides de toros con cromosoma Y mediante el uso de albúmina sérica bovina (ASB) en tres métodos propuestos: Doble centrifugación en ASB (M1); Centrifugación y migración en ASB (M2); Doble migración en ASB (M3). Las muestras de semen se conservaron durante $20-24$ horas a $5{ }^{\circ} \mathrm{C}$ y luego se congelaron en nitrógeno líquido. La variación en la proporción de espermatozoides con cromosoma Y (cuerpo F) se determinó usando una tinción con diclorhidrato de quinacrina. No se encontraron diferencias significativas en el porcentaje de cuerpos $\mathrm{F}(48.4 \pm 5.9 \%$ para el control y de $45.8 \pm 5.5$ a $47.2 \pm 4.9 \%$ para los tratamientos). La tasa de recuperación espermática fue de $50.7 \%$ para M1,36.2\% para M2 y $21.4 \%$ para M3 ( $<<0.01)$. Hubo una reducción significativa $(\mathrm{p}<0.01)$ de las características espermáticas por efecto del uso de ASB: la vitalidad espermática se redujo del $64.2 \%$ en el control a 42.5, 37.2 y $27.2 \%$ para M1, M2 y M3, respectivamente; la motilidad se redujo del $83.1 \%$ en el control a 48.1, 31.9 y $23.1 \%$ para M1, M2 y M3, respectivamente; el porcentaje de espermatozoides con membrana funcional se redujo del 64.6\% en el control a 42.7, 42.6 y $39.6 \%$ con M1, M2 y M3, respectivamente; y el porcentaje de espermatozoides vivos con acrosoma no reaccionado varió del 58.1\% en el control a 35.1, 30.2 y 20.5\% con M1, M2 y M3, respectivamente. Se observó una reducción general de las características espermáticas por efecto de la congelación en nitrógeno líquido $(\mathrm{p}<0.01)$, haciéndolas inviables.
\end{abstract}

Palabras clave: albúmina sérica bovina, sexado espermático, diclorhidrato de quinacrina, cuerpo $\mathrm{F}$, acrosoma

\footnotetext{
${ }^{1}$ Ganadera San Simón SAC, Cañete, Perú

${ }^{2}$ Departamento de Producción Animal, Facultad de Zootecnia, Universidad Nacional Agraria La Molina, Lima, Perú

${ }^{3}$ E-mail: gonzalo.wlad@gmail.com
}

Recibido: 2 de febrero de 2016

Aceptado para publicación: 4 de mayo de 2016 
This study was conducted to determine the possibility to vary the proportion of bull spermatozoa with Y chromosome by using bovine serum albumin (BSA) in three methods: Double centrifugation in BSA (M1); centrifugation and migration in BSA (M2); Double migration in BSA (M3). The sperm samples were stored for $20-24$ hours at $5{ }^{\circ} \mathrm{C}$ and then frozen in liquid nitrogen. The variation in the proportion of spermatozoa with $\mathrm{Y}$ chromosome (f-body) was determined by staining with quinacrine dihydrochloride. No significant difference was observed in the percentage of f-body $(48.4 \pm 5.9 \%$ for the control and from $45.8 \pm 5.5$ to $47.2 \pm 4.9 \%$ for the treatments. The spermatozoa retrieval rate was $50.7 \%$ for $\mathrm{M} 1,36.2 \%$ for $\mathrm{M} 2$, and $21.4 \%$ for M3 ( $<0.01$ ). The effect of ASB on sperm characteristics was significant $(\mathrm{p}<0.01)$ : the sperm vitality was reduced from $64.2 \%$ in the control to 42.5, 37.2 and $27.2 \%$ in M1, M2 and M3 respectively; motility was reduced from $83.1 \%$ in the control to $48.1,31.9$ and $23.1 \%$ in M1, M2 and M3 respectively; the percentage of sperm with functional membrane was reduced from $64.6 \%$ in the control to $42.7,42.6$ and $39.6 \%$ in M1, M2 and M3 respectively; and the percentage of live sperm with unreacted acrosome was $58.1 \%$ in the control and $35.1,30.2$ and $20.5 \%$ in M1, M2 and M3 respectively. Sperm characteristics of frozen semen were highly affected $(\mathrm{p}<0.01)$ making them unviable.

Key words: bovine serum albumin, sperm sexing, quinacrine dihydrochloride, f-body, acrosome

\section{INTRODUCCIÓN}

La posibilidad de poder controlar el sexo de la progenie siempre tuvo especial interés debido a consideraciones médicas en humanos y económicas en el campo de la producción animal. En especies de interés zootécnico como en el ganado bovino, la selección del sexo permitiría incrementar la intensidad de selección de un sexo respecto del otro y, por tanto, la habilidad trasmisora de caracteres productivos (Van Vleck y Everett, 1976).

Una forma para condicionar el sexo de la descendencia puede ser lograda por medio de la separación de los espermatozoides masculinos y femeninos, lo cual se denomina sexado de espermatozoides. En la década de los ochenta se iniciaron los procedimientos para establecer la selección del sexo por medio de la variación de cromatina entre los espermatozoides $\mathrm{X}$ e Y usando citometría de flujo, en la que los espermatozoides son mar- cados con el colorante fluorescente Hoechst 33342. Este colorante se fija al ADN y la fluorescencia emitida por cada cromosoma es proporcional a su tamaño. Así, los espermatozoides con cromosoma $\mathrm{X}$ emiten una señal mayor que aquellos con cromosoma Y. Cran et al. (1994) lograron separar espermatozoides $\mathrm{X}$ e $\mathrm{Y}$ del semen bovino con una precisión del $90 \%$; sin embargo, con una menor tasa $(17 \%)$ en la formación de blastocistos. En la actualidad, esta es la técnica que más se ha desarrollado y se utiliza de forma comercial para la obtención de pajillas de semen sexado de toros.

Otro método utiliza el diferencial de densidad que tiene cada tipo de espermatozoide, basado en la diferencia del contenido de ADN y proteína nuclear existente en la cabeza de los dos tipos de espermatozoides, y que en el bovino es de $0.06 \%$ (Palma, 2001). Esta característica fue aprovechada en trabajos de centrifugación mediante el uso de medios como Percoll ${ }^{\circledR}$ (Böttcher, 1996), Optipret ${ }^{\circledR}$ (Resende et al., 2009) y Bovipure ${ }^{\circledR}$ 
(Samardzija et al., 2006), que forman gradientes continuos donde se da un aumento gradual de la densidad desde la parte superior a la inferior, o gradientes discontinuos utilizando dos cámaras. Con los medios densos y la aplicación de fuerza gravitacional por centrifugación, fue posible provocar un desplazamiento diferencial entre los grupos de espermatozoides portadores del cromosoma X o Y (Costa, 2007).

En otros casos se utiliza la velocidad de migración en medios viscosos como yema de huevo disuelta en solución fisiológica (Schilling, 1966), albúmina sérica bovina ASB - (Ericcson et al., 1973) y albúmina sérica humana - ASH - (Hernández et al., 2008). El uso de medios elaborados con albúminas séricas en gradientes, sean continuos o discontinuos, son de los métodos más usados para lograr el sexado de espermatozoides en humanos; sin embargo los resultados en términos de eficacia en la tasa de sexado espermático logrado son muy discutidos. Se reportan fracciones con $85 \%$ de espermatozoides con cromosoma Y en humanos (Ericsson et al., 1973) y $72.7 \%$ en ovinos (Hadi y Al-Timimi, 2013), en tanto que Hernández et al. (2008) lograron separar espermatozoides de conejos portadores de cromosomas Y mediante simple migración en gradientes continuas de ASH sin centrifugación, obteniendo 73 y $23 \%$ de gazapos machos y hembras, respectivamente. No obstante, otros estudios muestran la inefectividad de dicho producto. En tal sentido, Beal et al. (1984) no lograron obtener diferencias en el sexo de la progenie con esperma bovino procesado en ASB, ni Zavos (1985) con semen de conejo procesado en albúmina.

El objetivo general de la presente investigación fue determinar si el uso de la albúmina sérica bovina en métodos de sexado de espermatozoides permite variar la proporción de espermatozoides con cromosoma $\mathrm{Y}$ en muestras seminales de toros. Para ello se plantearon como objetivos específicos: (1) Determinar la capacidad de sexado espermático que se puede lograr por el uso de albúmina sérica bovina en tres metodologías, (2) Evaluar el efecto de dichos procedimientos sobre las características espermáticas consideradas como indicadores usuales de calidad, $\mathrm{y}$ (3) Evaluar el efecto de la criopreservación sobre las características espermáticas de las muestras resultantes.

\section{Materiales y Métodos}

\section{Lugar de Ejecución}

La recolección de semen, el procedimiento de sexado y la evaluación de las características microscópicas de las muestras recuperadas se realizó en el Banco Nacional de Semen (BNS) de la Universidad Nacional Agraria La Molina (UNALM), localizada en la provincia y región Lima, Perú. La evaluación de la presencia de cuerpo F se efectuó en los laboratorios de reproducción animal del centro experimental «La Raya» de la Universidad Nacional de San Antonio Abad del Cusco (UNSAAC), en el distrito de Maranganí, provincia de Canchis, región Cusco, Perú. El trabajo de laboratorio se efectuó entre marzo y agosto de 2015.

\section{Población y Muestras}

Se usaron tres toros reproductores jóvenes del servicio de reproducción animal BNS - UNALM, sometidos a las mismas condiciones de manejo, alimentación y ambiente. Los toros fueron de las razas Brown Swiss, Holstein y Simmental. En cada caso, se recolectaron los eyaculados para someterlos a los procedimientos experimentales.

\section{Métodos para el Uso de ASB}

Doble centrifugación en ASB (MI)

Se empleó un aproximado de $200 \times 10^{6}$ espermatozoides en un volumen de $0.5 \mathrm{ml}$ de suspensión espermática sobre $4 \mathrm{ml}$ de una columna de ASB al 50\% de la solución ma- 
dre (equivalente al $6 \%$ de ASB disuelto en un medio de mantenimiento elaborado ${ }^{4}$ ) dentro de un tubo cónico de $14 \mathrm{ml}$ con tapa rosca. Se centrifugó a $120 \mathrm{G}$ durante $10 \mathrm{~min}$ a temperatura ambiente de $20-22{ }^{\circ} \mathrm{C}$; se recuperó $1.5 \mathrm{ml}$ de la fracción inferior del medio junto con el pellet de esperma. Se homogenizó y volvió a colocar sobre una segunda columna formada con $4 \mathrm{ml}$ de medio elaborado con solución madre de ASB al 100\% (equivalente al $12 \%$ de ASB), se volvió a centrifugar a $120 \mathrm{G}$ durante $10 \mathrm{~min}$ a temperatura ambiente. Se recuperó $2 \mathrm{ml}$ de la parte inferior del tubo junto con el pellet de esperma formado. Esta fracción fue disuelta con $4 \mathrm{ml}$ de medio de mantenimiento «MM» y fue centrifugada a $170 \mathrm{G}$ durante $5 \mathrm{~min}$ para retirar el exceso de ASB. Finalmente se recuperó $0.5 \mathrm{ml}$ del fondo del tubo junto con el pellet y el producto fue combinado con $3.0 \mathrm{ml}$ de dilutor comercial Andromed $®$.

\section{Migración y centrifugación en ASB (M2)}

Se empleó un aproximado de $200 \times 10^{6}$ espermatozoides y se siguió el procedimiento anterior hasta la primera centrifugación y recuperación del pellet de esperma. Este se homogenizó y volvió a colocar sobre una segunda columna formada con $2 \mathrm{ml}$ de una columna de ASB al $100 \%$ de solución madre (equivalente al $12 \%$ de $\mathrm{ASB}$ ) que estaba en una jeringa de $10 \mathrm{ml}$ con un tapón en la punta. Se incubó a $35^{\circ} \mathrm{C}$ durante $10 \mathrm{~min}$ en baño María, inclinado a $30^{\circ}$ para favorecer el desplazamiento de los espermatozoides. Luego se extrajo la jeringa y se retiró el tapón para eliminar $1.0 \mathrm{~m}$ de la parte más próxima a la punta de la jeringa. El resto, equivalente a $2.5 \mathrm{ml}$ del medio, fue colocado en un tubo de ensayo de $14 \mathrm{ml} \mathrm{y} \mathrm{mezclado} \mathrm{con} 4 \mathrm{ml}$ de medio de mantenimiento «MM»y fue centrifugado a $170 \mathrm{G}$ durante $5 \mathrm{~min}$ para poder retirar el exceso de ASB. Finalmente se retiró $6 \mathrm{ml}$ de la solución y se recuperaron
$0.5 \mathrm{ml}$ del fondo del tubo junto con el pellet para ser combinado con $3.0 \mathrm{ml}$ de dilutor comercial Andromed $\AA$.

\section{Doble migración en ASB (M3)}

Se utilizaron aproximadamente $200 \times 10^{6}$ espermatozoides contenidos en $0.5 \mathrm{ml}$ de suspensión espermática sobre $4 \mathrm{ml}$ de una columna de ASB al 50\% de la solución madre (equivalente al $6 \%$ de $\mathrm{ASB}$ ) dentro de una jeringa de $10 \mathrm{ml}$ con tapón en la punta. Se incubó a $35^{\circ} \mathrm{C}$ durante 15 min en baño María, inclinado a $30^{\circ}$ para favorecer el desplazamiento de los espermatozoides. Se extrajo la jeringa y se retiró el tapón eliminando 1.2 $\mathrm{ml}$ de fracción más próxima a la punta. Se recuperó $1.5 \mathrm{ml}$ correspondiente a la parte media de la columna de ASB. La fracción recuperada fue colocada sobre una segunda columna formada con $2 \mathrm{ml}$ de ASB al 100\% de solución madre (equivalente al $12 \%$ de ASB), contenida en una jeringa de $10 \mathrm{ml}$ con tapón en la punta. Se repitió el procedimiento de incubación, esta vez por $10 \mathrm{~min}$, se extrajo la jeringa, se retiró el tapón, se eliminó $1.0 \mathrm{ml}$ y se recuperó el resto del medio $(2.5 \mathrm{ml})$, colocándolo en un tubo de ensayo de $14 \mathrm{ml}$. Se mezcló con $4 \mathrm{ml}$ de medio de mantenimiento y se centrifugó a $170 \mathrm{G}$ durante 5 min para retirar el exceso de ASB. Finalmente se retiró $6 \mathrm{ml}$ de la solución y se recuperó $0.5 \mathrm{ml}$ del fondo del tubo junto con el pellet para ser combinado con $3.0 \mathrm{ml}$ de dilutor comercial

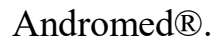

\section{Control}

Se utilizó un volumen de $0.5 \mathrm{ml}$ de suspensión espermática de la misma muestra utilizada para los métodos experimentales (200x $10^{6}$ espermatozoides). Se colocó en un tubo de ensayo con tapa rosca y fue diluida con Andromed ${ }^{\circledR}$ hasta llegar a un volumen de $3.5 \mathrm{ml}$.

${ }^{4}$ Medio de mantenimiento $« M M »$ elaborado con TRIS: $225 \mathrm{mM}$, ácido cítrico: $78 \mathrm{mM}$ y fructosa: $20.9 \mathrm{mM}$ 


\section{Congelación de las Muestras}

Las muestras de cada método y del control fueron homogenizadas y envasadas en siete pajillas de $0.5 \mathrm{ml}$ por grupo. Una pajilla de cada grupo fue utilizada para determinar las características espermáticas de 0-2 h después de la aplicación de métodos de sexado, siendo consideradas como muestras frescas. Las seis pajillas restantes de cada grupo fueron conservadas a $5{ }^{\circ} \mathrm{C}$ durante $20-24 \mathrm{~h}$, empleándose una pajilla por grupo para evaluar las características espermáticas posrefrigeración. Las cinco pajillas restantes de cada grupo fueron congeladas en nitrógeno líquido. Dos pajillas de cada grupo fueron utilizadas para la evaluación poscongelación y el resto de las pajillas se utilizaron para la observación del cuerpo F.

Este procedimiento se repitió cinco veces, extrayendo en cada ocasión un eyaculado por cada toro utilizado en el experimento, haciendo un total de 15 eyaculados que se utilizaron para cada uno de los métodos propuestos y el control.

\section{Obtención de Datos}

La cámara de Neubauer fue utilizada para evaluar la tasa de recuperación espermática de las muestras obtenidas luego de la aplicación de los tres métodos y del grupo control.

Se usó el colorante fluorescente diclorhidrato de quinacrina para determinar la variación en la proporción de espermatozoides con cromosoma Y. Esa tinción permite visualizar el cuerpo F (manifestación visual del cromosoma Y) utilizando las metodologías descritas por Červenka et al. (1971) y Böttcher (1996). Se observaron en microscopio de fluorescencia con una longitud de onda de 450-500 nm y con objetivos de 40X.
Se utilizó la técnica citológica de tinción compuesta de azul tripán - solución giemsa, descrita por Kovács y Foote (1992) para determinar la cantidad de espermatozoides vivos y muertos, así como los que pudieron sufrir reacción acrosómica. Con este último método se pueden distinguir cuatro categorías de espermatozoides: (1) vivos con acrosoma íntegro, (2) vivos con acrosoma dañado, (3) muertos con acrosoma íntegro, (4) muertos con acrosoma dañado. Los espermatozoides vivos muestran la región posacrosomal de color ligeramente azulado o translucido debido a que la membrana plasmática de estas células repele el colorante azul tripán, mientras que los muertos presentan un color azul oscuro. El acrosoma estará íntegro cuando presenta un color violeta debido a la afinidad de la solución giemsa y está dañado o ha reaccionado cuando se observa de color translúcido. La evaluación se realizó con un microscopio de contraste de fase y objetivos de $40 X$.

La prueba de resistencia osmótica (HOS) se realizó para evaluar la funcionalidad de la membrana plasmática. Para esto, las muestras espermáticas fueron cultivadas por una hora en una solución hipoosmótica elaborada con ácido cítrico y citrato de sodio, siguiendo las metodologías descritas por Jeyendran et al. (1984) y Correa y Zavos (1994).

\section{Análisis Estadístico}

Los valores porcentuales hallados fueron transformados mediante arco seno. Para la evaluación de las características consideradas en estudio, se empleó un diseño de bloques con submuestreo, cuyo modelo matemático lineal fue: $\mathrm{Y}_{\mathrm{ijk} \mathrm{k}}=\mu+\mathrm{M}_{\mathrm{i}}+\mathrm{B}_{\mathrm{j}}+(\mathrm{MxB})_{\mathrm{ijk}}$ $+\mathrm{e}_{\mathrm{ijk} \mathrm{l}}$, donde $\mathrm{Y}_{\mathrm{ijkl}}$ es la variable dependiente o respuesta, $\mu$ es la media general, $M_{i}$ es el efecto del i-esimo tratamiento o método de sexado (M1, M2, M3, control), $B_{j}$ es el efec- 
to del $\mathrm{j}$-ésimo bloque (toro 1 , toro 2 , toro 3 ), $(\mathrm{MxB})_{\mathrm{ijk}}$ es el error de observación, y $\mathrm{e}_{\mathrm{ijk1}}$ es el error experimental. En todos los análisis estadísticos se utilizó el programa SAS (Statistical Analysis System) v. 8.0.

\section{Resultados y Discusión}

\section{Tasa de Recuperación Espermática}

Los porcentajes de M1 y M2 se presentan en el Cuadro 1. Estos valores fueron superiores a otros resultados reportados en la literatura. Así, Correa et al. (1997) obtuvieron $16.7 \%$ de recuperación con la técnica swim up, en tanto que Chen et al. (1997) con tratamientos de migración-centrifugación pudieron recuperar el 9.3 y $17.5 \%$ de espermatozoides a temperatura ambiente y $37^{\circ} \mathrm{C}$, respectivamente.

En el caso de la centrifugación en M1 y M2 se pudo observar la formación de un pellet de regular tamaño, lo que permitió obtener mayores niveles de recuperación de espermatozoides. Se podría decir que incrementando el tiempo de centrifugación se podría recuperar una mayor cantidad de espermatozoides; sin embargo, la formación del pellet implica que los espermatozoides se aglutinen ocasionando un fuerte deterioro de los mismos.
En forma similar, el resultado de M3 fue más alto que el obtenido por Costa (2007) con una tasa media de $18.3 \%$ en una técnica de migración swim up, mientras que Flaherty et al. (1997) pudieron recuperar una media del $11.1 \%$. En otras investigaciones, Rose y Wong (1998) lograron recuperar el 3.9\% y Chen et al. (1997) entre el 7.0 y $9.3 \%$, con dos procesos de migración en ASH a temperatura ambiente. El mejor resultado del presente estudio podría deberse al tipo y al tiempo de migración empleado, ya que en este caso se efectuó una migración hacia abajo («swim down») en un tiempo total de $25 \mathrm{~min}$ a $36^{\circ} \mathrm{C}$, en tanto que en los trabajos revisados se utilizaron periodos de migración más largos que van desde 45 min en gradientes continuas (Rose y Wong, 1998) durante $1.5 \mathrm{~h}$ (Chen et al., 1997), y con migraciones hacia arriba («swim up»), que ocasiona la presencia de una menor cantidad de espermatozoides en las muestras más distales del núcleo de partida de las muestras, que es un pellet previamente formado por sedimentación mediante centrifugación.

\section{Características Espermáticas}

\section{Vitalidad espermática}

En las características espermáticas de las muestras frescas (Cuadro 2), se observó una disminución en el porcentaje de esper-

Cuadro 1. Número y porcentaje de espermatozoides recuperados con tres métodos de sexado de espermatozoides de bovino utilizando albúmina sérica bovina

\begin{tabular}{lcccc}
\hline Unidad & Control & $\begin{array}{c}\text { Doble } \\
\text { centrifugación } \\
\text { M1 }\end{array}$ & $\begin{array}{c}\text { Centrifugación } \\
+ \text { migración } \\
\text { M2 }\end{array}$ & $\begin{array}{c}\text { Doble } \\
\text { migración hacia } \\
\text { abajo } \\
\text { M3 }\end{array}$ \\
\hline $\begin{array}{l}\text { Promedio } \\
\pm \mathrm{DE}\end{array}$ & $\begin{array}{c}201.25 \times 10^{6}(\mathrm{a}) \\
\pm 20.45 \times 10^{6}\end{array}$ & $\begin{array}{c}101.60 \times 10^{6}(\mathrm{~b}) \\
\pm 9.40 \times 10^{6}\end{array}$ & $\begin{array}{c}72.28 \times 10^{6}(\mathrm{c}) \\
\pm 6.49 \times 10^{6}\end{array}$ & $\begin{array}{c}43.77 \times 10^{6}(\mathrm{~d}) \\
\pm 4.31 \times 10^{6}\end{array}$ \\
$\begin{array}{l}\text { Porcentaje } \\
\text { del control }\end{array}$ & $100 \%$ & $50.7 \%$ & $36.2 \%$ & $21.4 \%$ \\
\hline a,b,c,d Medias con letras diferentes indican diferencia estadística $(\mathrm{p}<0.01)$ &
\end{tabular}


Cuadro 2. Características espermáticas en muestras frescas de semen bovino según el método de sexado

\begin{tabular}{lcccc}
\hline Unidad & Control & $\begin{array}{c}\text { Doble } \\
\text { centrifugación } \\
\text { M1 }\end{array}$ & $\begin{array}{c}\text { Centrifugación } \\
+ \text { migración } \\
\text { M2 }\end{array}$ & $\begin{array}{c}\text { Doble } \\
\text { migración } \\
\text { M3 }\end{array}$ \\
\hline Vitalidad \pm & $64.24(\mathrm{a}) \pm$ & $42.53(\mathrm{~b}) \pm$ & $37.23(\mathrm{~b}) \pm$ & $27.23(\mathrm{c}) \pm$ \\
$\mathrm{DE}, \%$ & $10.03 \%$ & $7.81 \%$ & $10.70 \%$ & $10.19 \%$ \\
Motilidad \pm & $83.11(\mathrm{a}) \pm$ & $48.11(\mathrm{~b}) \pm$ & $31.89(\mathrm{c}) \pm$ & $23.11(\mathrm{~d}) \pm$ \\
$\mathrm{DE}, \%$ & $5.63 \%$ & $10.29 \%$ & $10.02 \%$ & $11.63 \%$ \\
$\mathrm{HOS}$ test + \pm & $64.62(\mathrm{a}) \pm$ & $42.74(\mathrm{~b}) \pm$ & $42.58(\mathrm{~b}) \pm$ & $39.63(\mathrm{~b}) \pm$ \\
$\mathrm{DE}, \%$ & $10.15 \%$ & $10.46 \%$ & $11.97 \%$ & $10.61 \%$ \\
Spz VAI ${ }^{1} \pm$ & $58.12(\mathrm{a}) \pm$ & $35.10(\mathrm{~b}) \pm$ & $30.16(\mathrm{~b}) \pm$ & $20.48(\mathrm{c}) \pm$ \\
$\mathrm{DE}, \%$ & $11.16 \%$ & $9.50 \%$ & $11.28 \%$ & $10.13 \%$ \\
\hline${ }^{\mathrm{a}, \mathrm{b}, \mathrm{c}, \mathrm{d}, \mathrm{d}}$ Medias con letras diferentes dentro de filas indican diferencia estadística $(\mathrm{p}<0.01)$ \\
${ }^{1}$ Espermatozoide vivo con acrosoma íntegro
\end{tabular}

Cuadro 3. Resultados de las características espermáticas evaluadas en muestras refrigeradas

\begin{tabular}{|c|c|c|c|c|}
\hline Unidad & Control & $\begin{array}{c}\text { Doble } \\
\text { centrifugación } \\
\text { M1 }\end{array}$ & $\begin{array}{c}\text { Centrifugación } \\
+ \text { migración } \\
\text { M2 }\end{array}$ & $\begin{array}{c}\text { Doble } \\
\text { migración } \\
\text { M3 }\end{array}$ \\
\hline $\begin{array}{l}\text { Vitalidad } \pm \\
\text { DE, \% }\end{array}$ & $\begin{array}{c}56.38(\mathrm{a}) \pm \\
10.38 \%\end{array}$ & $\begin{array}{c}41.87(b) \pm \\
10.19 \%\end{array}$ & $\begin{array}{c}30.38(\mathrm{c}) \pm \\
10.66 \%\end{array}$ & $\begin{array}{c}29.79(\mathrm{c}) \pm \\
11.96 \%\end{array}$ \\
\hline $\begin{array}{l}\text { Motilidad } \pm \\
\text { DE, \% }\end{array}$ & $\begin{array}{c}84.45(\mathrm{a}) \pm \\
7.42 \%\end{array}$ & $\begin{array}{c}46.22(b) \pm \\
15.15 \%\end{array}$ & $\begin{array}{c}27.33(\mathrm{c}) \pm \\
12.77 \%\end{array}$ & $\begin{array}{c}17.56(\mathrm{~d}) \pm \\
12.85 \%\end{array}$ \\
\hline $\begin{array}{l}\text { HOS test }+ \pm \\
\text { DE, } \%\end{array}$ & $\begin{array}{c}60.64(\mathrm{a}) \pm \\
7.24 \%\end{array}$ & $\begin{array}{c}44.71(b) \pm \\
8.97 \%\end{array}$ & $\begin{array}{c}42.22(\mathrm{bc}) \pm \\
7.58 \%\end{array}$ & $\begin{array}{c}37.52(\mathrm{c}) \pm \\
7.96 \%\end{array}$ \\
\hline $\begin{array}{l}\text { Spz VAI }{ }^{1} \pm \\
\text { DE, } \%\end{array}$ & $\begin{array}{c}52.65(\mathrm{a}) \pm \\
10.78 \%\end{array}$ & $\begin{array}{c}35.70(b) \pm \\
11.23 \%\end{array}$ & $\begin{array}{c}23.11(\mathrm{c}) \pm \\
9.19 \%\end{array}$ & $\begin{array}{l}23.44(\mathrm{c}) \\
\pm 10.29 \%\end{array}$ \\
\hline
\end{tabular}

matozoides vivos tras ser sometidos a los tres métodos de sexado con el uso de ASB $(\mathrm{p}<0.01)$. El valor promedio del control fue bastante superior al resto de promedios, en tanto que M1 fue similar a M2 y estos fueron superiores a M3.

En el caso de las muestras refrigeradas, el promedio del control fue superior a los tres métodos $(\mathrm{p}<0.01)$, mientras que M1 fue superior a M2 y M3 (Cuadro 3). En el caso de las muestras congeladas en general, se observó una reducción substancial de la vitalidad respecto de los valores observados en las muestras frescas y refrigeradas; asimismo, el promedio del control fue superior a los obtenidos en los otros grupos experimentales $(\mathrm{p}<0.01)$. 
Cuadro 4. Resultados de las características espermáticas evaluadas en muestras congeladas

\begin{tabular}{|c|c|c|c|c|}
\hline Unidad & Control & $\begin{array}{c}\text { Doble } \\
\text { centrifugación } \\
\text { M1 }\end{array}$ & $\begin{array}{l}\text { Centrifugación } \\
\text { + migración } \\
\text { M2 }\end{array}$ & $\begin{array}{c}\text { Doble } \\
\text { migración } \\
\text { M3 }\end{array}$ \\
\hline $\begin{array}{l}\text { Vitalidad } \pm \\
\text { DE, \% }\end{array}$ & $\begin{array}{c}42.64(\mathrm{a}) \pm \\
13.10 \%\end{array}$ & $\begin{array}{c}25.13(\mathrm{~b}) \pm \\
7.96 \%\end{array}$ & $\begin{array}{c}18.22(\mathrm{c}) \pm \\
8.18 \%\end{array}$ & $\begin{array}{c}14.25(\mathrm{c}) \pm \\
7.93 \%\end{array}$ \\
\hline $\begin{array}{l}\text { Motilidad } \pm \\
\text { DE, \% }\end{array}$ & $\begin{array}{c}54.22(\mathrm{a}) \pm \\
11.92 \%\end{array}$ & $\begin{array}{c}29.44(b) \pm \\
10.72 \%\end{array}$ & $\begin{array}{c}10.33(\mathrm{c}) \pm \\
7.56 \%\end{array}$ & $\begin{array}{c}4.55(\mathrm{c}) \pm \\
3.18 \%\end{array}$ \\
\hline $\begin{array}{l}\text { HOS test }+ \pm \\
\text { DE, \% }\end{array}$ & $\begin{array}{c}46.07 \text { (a) } \pm \\
10.19 \%\end{array}$ & $\begin{array}{c}41.43(\mathrm{~b}) \pm \\
9.49 \%\end{array}$ & $\begin{array}{c}39.14(\mathrm{~b}) \pm \\
9.99 \%\end{array}$ & $\begin{array}{c}39.17(\mathrm{~b}) \pm \\
8.28 \%\end{array}$ \\
\hline $\begin{array}{l}\text { Spz V AI }{ }^{1} \pm \\
\text { DE, } \%\end{array}$ & $\begin{array}{c}31.11(\mathrm{a}) \pm \\
11.63 \%\end{array}$ & $\begin{array}{c}16.38(\mathrm{~b}) \pm \\
7.47 \%\end{array}$ & $\begin{array}{c}10.98(\mathrm{bc}) \pm \\
7.19 \%\end{array}$ & $\begin{array}{c}7.86(\mathrm{c}) \pm \\
5.42 \%\end{array}$ \\
\hline
\end{tabular}

Los resultados difieren de los presentados por Costa (2007), quien consiguió 61 y $69 \%$ de espermatozoides vivos en el grupo control y con el método de migración swim up, respectivamente, y de Palomo (1995) con 63.0 y $73.6 \%$ en el grupo control y con la técnica de migración swim up, respectivamente. No obstante, los resultados de vitalidad de este último autor, al utilizar la técnica de centrifugación en Ficoll, fue de 61.3\%.

\section{Motilidad espermática}

Se observó una reducción en el porcentaje de motilidad de las muestras frescas en los tres métodos con respecto del control $(\mathrm{p}<0.01)$. Asimismo, los valores de M1, M2 y M3 fueron estadísticamente diferentes entre sí, teniendo M1 el mejor resultado (Cuadro 2). Los resultados de las muestras refrigeradas tuvieron un comportamiento similar al de las muestras frescas (Cuadro 3). En el caso de las muestras congeladas (Cuadro 3), el valor del grupo control fue muy superior a los tres métodos, especialmente a M2 y M3 $(\mathrm{p}<0.01)$.

Los resultados obtenidos fueron inferiores a los obtenidos por David et al. (1977), quienes observaron un incremento en motilidad con el incremento de la concentración de ASB en la gradiente utilizada en metodologías de un sola migración, pasando de $60 \%$ con gradientes de ASB al 10\% hasta $95 \%$ cuando se utilizaban gradientes de ASB al 25\%. Asimismo, Beal et al. (1984) obtuvieron $35 \%$ en muestras no tratadas y $60 \%$ en muestras procesadas con ASB en muestras que habían sido congeladas en nitrógeno líquido. Por otro lado, Chen et al. (1997) en muestras seminales humanas encontraron valores de 99.3\%, mientras que Samardzija et al. (2006) obtuvieron $70 \%$ de motilidad en las muestras tratadas de bovino.

En el presente estudio, en M3 se obtuvieron valores de motilidad de $23.11 \%$, cifra muy inferior a las presentadas por otros autores y donde se muestran incrementos en la tasa de motilidad respecto de sus grupos de control. En este caso, el resultado fue incluso menor en comparación con los métodos que basan su principio en la centrifugación, como son M1 y M2, que se creía que podrían ocasionar un mayor deterioro. Se puede inferir que el mayor tiempo de exposición a ASB ocasionó una notable reducción de esta condición, indistintamente del método propuesto para el desplazamiento físico. 


\section{Funcionalidad de membrana plasmática} (HOS)

En el análisis de las muestras frescas, se observó una reducción general en la funcionalidad de membrana plasmática de las muestras sometidas a los tres métodos de sexado con uso de ASB $(\mathrm{p}<0.01)$ respecto al grupo control; sin embargo, hubo diferencias entre los valores de los tres métodos (Cuadro 2). En las muestras refrigeradas (Cuadro 3), el grupo control mantuvo un promedio de espermatozoides con membrana funcional superior a los promedios de los otros tres grupos $(\mathrm{p}<0.01)$. M1 fue, además, estadísticamente superior a M3. En el caso de las muestras congeladas (Cuadro 4) no hubo diferencias entre métodos, pero estos fueron inferiores al promedio del control $(\mathrm{p}<0.01)$.

Los resultados contradicen las observaciones de Correa et al. (1997), Samardzija et al. (2006) y Oliveira et al. (2011b) que, en general, mostraron incrementos en la proporción de espermatozoides con membrana plasmática funcional luego de ser sometidos a diferentes métodos de sexado.

En M2 y M1, aunque existió acción mecánica por la aplicación de fuerza centrífuga, esta no ocasionó un deterioro superior al observado con M3, por lo que se puede inferir que la acción mecánica no fue significativa para incrementar el grado de deterioro en esta característica. Tal y como lo refieren otros autores (Palomo, 1995; Bötcher, 1996; Samardzija et al., 2006), se puede atribuir que el deterioro se debe al proceso de capacitación ocurrida cuando las muestras seminales son sometidas a procedimientos de migración y centrifugación en gradientes o columnas de densidad incrementada, como las que se utilizaron en este estudio.

Espermatozoides vivos con acrosoma integro «VAI»

En las muestras frescas (Cuadro 2), el control mantuvo un promedio de $58.12 \%$ de- espermatozoides vivos con acrosoma no reaccionado, pero en las muestras que fueron procesadas con ASB se observó una reducción significativa $(\mathrm{p}<0.01)$, donde M1 y M2 fueron estadísticamente superiores a M3 (Cuadro 2). En las muestras refrigeradas persistió la condición observada en las muestras frescas (Cuadro 3), en tanto que en las muestras congeladas se observó una reducción marcada del porcentaje de espermatozoides vivos con acrosoma no reaccionado en todos los grupos, incluyendo a las muestras del grupo control; sin embargo, se mantuvo la condición de superioridad del control sobre el resto (Cuadro 4; $\mathrm{p}<0.01)$.

Los valores obtenidos fueron diferentes a los de Resende et al. (2009), quienes obtuvieron una mejora de espermatozoides VAI (19\%) mediante centrifugación en gradientes Percoll ${ }^{\circledR}$ en relación con el grupo control (10\%). Por otro lado, Costa (2007), utilizando una técnica de centrifugación en gradientes de densidad, obtuvo un $7 \%$ de espermatozoides VAI y con la técnica swim up logró recuperar un promedio de $9.75 \%$, indicando que esas técnicas promovían el incremento de espermatozoides que sufrían una capacitación prematura y que el protocolo de centrifugación utilizado ocasionaba un incremento del porcentaje de espermatozoides con membrana acrosomal dañada.

Oliveira et al. (2011a), realizando estudios de fluorescencia, evaluaron el efecto del uso de gradientes de Percoll ${ }^{\circledR}$ sobre características celulares análogas, hallando 59\% de espermatozoides con acrosoma intacto en el control y $38.2 \%$ en el tratamiento utilizado. La membrana acrosómica, al estar expuesta al medio de mantenimiento y a las columnas de ASB, sufrió un deterioro estructural, lo que ocasionó la reacción acrosómica prematura, aspecto que se demuestra con los resultados de la presente investigación.

El proceso de congelación ocasionó una reducción en la proporción de espermatozoides VAI en todos los grupos evaluados, 
Cuadro 5. Porcentaje de espermatozoides con cuerpo $\mathrm{F}$ en muestras de semen bovino sometidas a tres métodos de sexado con el uso de ASB

\begin{tabular}{lcccc}
\hline Unidad & $\begin{array}{c}\text { Control } \\
\text { M0 }\end{array}$ & $\begin{array}{c}\text { Doble } \\
\text { centrifugación } \\
\text { M1 }\end{array}$ & $\begin{array}{c}\text { Centrifugación } \\
+ \text { migración } \\
\text { M2 }\end{array}$ & $\begin{array}{c}\text { Doble } \\
\text { migración } \\
\text { M3 }\end{array}$ \\
\hline Promedio \pm & $48.41(\mathrm{a}) \pm$ & $46.15(\mathrm{a}) \pm$ & $45.82(\mathrm{a}) \pm$ & $47.18(\mathrm{a}) \pm$ \\
DE, $\%$ & $5.93 \%$ & $5.86 \%$ & $5.47 \%$ & $4.92 \%$ \\
\hline
\end{tabular}

Medias con letras similares no indican dife rencia estadística

la cual pudo deberse principalmente a la fractura de las membranas celulares que se produjeron por efecto de la formación de cristales de agua. Así, Rubio-Guillén et al. (2007) observaron una reducción en la población de espermatozoides VAI del $88.8 \%$ en muestras frescas al $52.2 \%$ en muestras congeladas.

\section{Separación Espermática}

La aplicación de los métodos propuestos para uso de ASB (M1, M2, M3) no ocasionaron una variación en la proporción de espermatozoides con cuerpo $\mathrm{F}$ ( $\mathrm{p}>0.05$ ), aunque se pudo observar pequeñas diferencias numéricas entre estos (Cuadro 5).

Ericsson et al. (1973) obtuvieron fracciones de semen humano con $85.0 \%$ de espermatozoides con cromosoma Y, mientras que Corson et al. (1984), replicando la metodología desarrollada por Ericsson et al. (1973), obtuvieron muestras espermáticas con las que se logró obtener 28 varones de un total de 35 concepciones. Asimismo, Chen et al. (1997), con el uso de gradientes de ASH, consiguieron un incremento ligero pero significativo a favor de espermatozoides con cromosoma X. Por otro lado, Ueda y Yanagimachi (1987), replicando la metodología desarrollada por Ericsson et al. (1973), obtuvieron una diferencia significativa, 45.8 vs $43.1 \%$, de espermatozoides con cuerpos F luego de ser tratadas con albúmina en relación con el control, pero con una gran varia- ción, de allí que dichos autores pusieron en duda la efectividad del método para logar un incremento en la proporción de espermatozoides con el cromosoma Y.

Por otro lado, Hernández et al. (2008), trabajando con semen de conejo, obtuvieron $72.7 \%$ de crías machos al inseminar conejas con la fracción de espermatozoides que se encontraron en una gradiente de $20 \%$ de $\mathrm{ASH}$, en tanto que Hadi y Al-Timimi (2013), trabajando con semen ovino, incrementaron la proporción de espermatozoides portadores del cromosoma Y al 72.7 y $54.5 \%$ usando columnas de ASB al $8 \%$ en procedimientos de migración y centrifugación con $200 \mathrm{G}$ y $300 \mathrm{G}$, respectivamente, e incrementándose al 81.8 y $63.6 \%$ cuando se utilizaron gradientes en bifase de 16 y $8 \%$ de ASB, respectivamente.

Otras investigaciones tuvieron resultaron similares a los del presente estudio. Así, Beal et al. (1984), utilizando gradientes discontinuos de ASB con semen bovino, y Zavos (1985), utilizando muestras espermáticas de conejos resultantes del proceso de sedimentación en albúmina, no lograron diferencias importantes en el sexo de los animales nacidos por inseminación artificial con el semen sexado.

Es posible que la variación observada en la frecuencia de los espermatozoides portadores de cuerpo F, luego de las tinciones con quinacrina, refleje una verdadera proporción de sexos gaméticos, pero también pue- 
de representar una desigual captación del colorante quinacrina por parte de 1 os cromosomas Y, la decoloración del colorante antes del análisis o las variaciones en el material cromosómico, tal como lo señaló Martin (1990). Roberts y Goodall (1976) al igual que David et al. (1977) concluyeron que la determinación de los cuerpos F está condicionada al criterio y la experiencia del observador al momento de evaluar las muestras, además de la existencia de cierta dependencia en la eficiencia de la detección del cromosoma $\mathrm{Y}$ mediante la coloración con quinacrina.

\section{Conclusiones}

- El empleo de albúmina sérica bovina (ASB) con las metodologías de doble centrifugación en ASB, migración y centrifugación en ASB, y doble migración en ASB, no permitió alterar la proporción de espermatozoides bovinos con cuerpo $\mathrm{F}$.

- El método de doble centrifugación permitió obtener una mayor tasa de recuperación de espermatozoides.

- El mayor tiempo de exposición a ASB, indistintamente de los métodos propuestos para su utilización, ocasionó un deterioro significativo de las características espermáticas.

- El efecto de la congelación ocasionó un deterioro de las características espermáticas, haciéndolas inviables para su uso posterior en inseminación artificial.

\section{Literatura Citada}

1. Beal WE, White LM, Garner DL. 1984. Sex ratio after insemination of bovine spermatozoa isolated using a bovine serum albumin gradient. J Anim Sci 58: 1432-1436.

2. Böttcher F. 1996. Pré-seleção sexual in vitro comparação entre os métodos de Percoll e Swim up e proposta de nova técnica. PhD thesis. Brasil: Instituto de Biologia da Universidade Estadual de Campinas. 72 p.

3. Červenka J, Jacobson DE, Gorlin RJ. 1971. Fluorescing structures of human metaphase chromosomes. Detection of «Y body». Am J Hum Gen 23: 317-324.

4. Chen М, Gии Н, Но ES. 1997. Efficiency of sex pre-selection of spermatozoa by albumin separation method evaluated by double-labelled fluorescence in situ hybridization. Hum Reprod 12: 1920-1926. doi: 10.1093/ humrep/12.9.1920

5. Correa JR, Zavos PM. 1994. The hypoosmotic swelling test: its employment as an assay to evaluate the functional integrity of frozen-thawed bovine sperm membrane. Theriogenology 42: 351-360. doi: 10.1016/0093691X(94)90280-1

6. Correa RJ, Panayota N, Zarmakoupis-Zavos N, Zavos PM. 1997. Quantitative and qualitative characteristics of frozen-thawed bovine spermatozoa recovered via a conventional a standardized swim-up technique. Tohoku J Exp Med 181: 267-274.

7. Corson SL, Batser FR, Alexander NJ, Schlaff S, Otis C. 1984. Sex selection by sperm separation and insemination. Fertil Steril 42: 756-760.

8. Costa A. 2007. Influência do método de separação dos espermatozóides viáveis («Swim up») na eficiência de seleção do sexo de bovinos por gradiente descontínuo de densidade e o impacto no melhoramento genético animal. MSc tesis. São Paulo. Brasil: Universidade Estadual Paulista. 88 p.

9. Cran DG, Cochrane DJ, Johnson L, Wei H, Lu HK, Polge C. 1994. Separation of X- and Y- chromosome bearing bovine sperm by flow cytometry for use on IVF. Theriogenology 41: 183. doi: 10.1016/S0093-691X(05)80093-7

10. David G, Jeulin C, Boyce A, Schwartz D. 1977. Motility and percentage of Yand YY-bearing spermatozoa in human 
semen samples after passage through bovine serum albumin. J Reprod Fert 50: 377-379.

11. Ericsson JR, Langevin CN, Nishino M. 1973. Isolation of fractions rich in human Y sperm. Nature 246: 421-424. doi: $10.1038 / 246421 \mathrm{a} 0$

12. Flaherty SP, Michalowska J, Swann NJ, Dmowski WP, Matthews CD, Aitken RJ. 1997. Albumin gradients do not enrich Y-bearing human spermatozoa. Hum Reprod 12: 938-942.

13. Hadi S, Al-Timimi IH. 2013. Separation of Y-chromosome bearing ram's sperms using an albumin gradient technique and identification of embryos by PCR. AL-Qadisiya J Vet Med Sci 12: 144-151.

14. Hernández P, Fernández R, Reyes $C$, Cerezo P, Echegaray L, Mendoza B. 2008. Separación de espermatozoides «Y» de eyaculado de conejo por medio de gradientes de densidad de albúmina sérica humana. Rev Salud Anim 30: 45-49.

15. Jeyendran $R$, Van der Ven $H$, PérezPeláez, M, Grabo B, Zaneveld L. 1984. Development of an assay to assess the functional integrity of the human sperm membrane and its relationship to other semen characteristics. J Reprod Fertil 70: 219-228.

16. Kovács A, Foote RH. 1992. Viability and acrosome staining of bull, boar and rabbit spermatozoa. Biotech Histochem 67: 119-124.

17. Martin RH. 1990. Sex ratio among sperm cells. Am J Hum Genet 47: 349351.

18. Oliveira LZ, Arruda RP, Celeghini ECC, Andrade AFC, Hossepian de Lima VFM. 2011b. Taxa de recuperação e características espermáticas após a sexagem por centrifugação em gradiente de densidade en espermatozoides descongelados. Rev Bras Reprod Anim 35: 41-48.

19. Oliveira LZ, Arruda RP, Celeghini ECC, Andrade AFC, Perini AP, Resende MV, Miguel MCV, et al. 2011a. Effects of discontinuous Percoll gradient centrifugation on the quality of bovine spermatozoa evaluated with computer-assisted semen analysis and fluorescent probes association. Andrologia 44: 9-15. doi: 10.1111/j.14390272.2010.01096.x

20. Palma G 2001. Biotecnología de la reproducción. Argentina: Ed INTA. 704 p.

21. Palomo MJ. 1995. Efecto del tratamiento de los espermatozoides sobre la fecundación in vitro en el caprino. Tesis Doctoral. España: Universidad Autónoma de Barcelona. 193 p.

22. Resende MV, Barbosa BM, Perecin F, Oliveira AA, Costa A, Hossepina de Lima VFM. 2009. Separation of $\mathrm{x}$ bearing bovine sperm by centrifugation in continuous Percoll ${ }^{\circledR}$ and Optiprep ${ }^{\circledR}$ density gradient: effect in sperm viability and in vitro embryo production. Ciênc Anim Bra 10: 581-587.

23. Roberts AM, Goodall H. 1976. Y chromosome visibility in quinacrinastained spermatozoa. Nature 262: 493 494. doi: $10.1038 / 262493 \mathrm{a} 0$

24. Rose GA, Wong A. 1998. Experiences in Hong Kong with theory and practice of the albumin column method of sperm separation for sex selection. Hum Reprod 13: 146-149.

25. Rubio-Guillén J, Gonzáles D, Gonzáles Y, Madrid-Bury N, Quintero-Moreno A. 2007. ¿Puede el ORT complementar las pruebas clásicas de valoración seminal y predecir la fertilidad en toros? En: XX Reunión Asociación Latinoamericana de Producción Animal. Cusco, Perú.

26. Samardzija M, Karadjole M, Getz I, Makek, Z, Cergolj M, Dobranic T. 2006. Effects of bovine spermatozoa preparation on embryonic development in vitro. Reprod Biol Endocrinol 4: 58. doi: 10.1186/1477-7827-4-58

27. Schilling E. 1966. Experiments in sedimentation and centrifugation of bull spermatozoa and the sex ratio of born calves. J Reprod Fert 11: 469-472. 
28. Ueda K, Yanagimachi R. 1987. Sperm chromosome analysis as a new system to test human $\mathrm{X}$ - and Y-sperm separation. Gamete Res 17: 221-228. doi: 10.1002/ mrd.1120170305

29. Van Vleck LD, Everett RW. 1976. Genetic value of sexed semen to procedure dairy heifers. J Dairy Sci 59: 1802-1807. doi: 10.3168/jds.S00220302(76)84440-2

30. Zavos PM. 1985. Sperm separation attempts via the use of albumin gradients in rabbits. Theriogenology 23: 875-879. doi: 10.1016/0093-691X(85)90005-6 